\title{
Inferring Extinctions III: A cost-benefit framework for listing extinct species
}

H. R. Akçakaya ${ }^{\mathrm{a}, \mathrm{b}, *}$, David A. Keith, ${ }^{\mathrm{c}, \mathrm{d}, \mathrm{b}}$, Mark Burgman ${ }^{\mathrm{e}, \mathrm{f}}$, Stuart H. M.

Butchart $^{\mathrm{g}, \mathrm{h}, \mathrm{b}}$, Michael Hoffmann ${ }^{\mathrm{b}, \mathrm{i}}$, Helen M. Regan ${ }^{\mathrm{j}, \mathrm{b}}$, Ian Harrison ${ }^{\mathrm{k}, \mathrm{b}}$, Elizabeth Boakes $^{1}$

${ }^{a}$ Department of Ecology and Evolution, Stony Brook University, Stony Brook, NY 11794, U.S.A. ${ }^{b} I U C N$ Species Survival Commission, International Union for Conservation of Nature, Gland, Switzerland

${ }^{c}$ Centre for Ecosystem Science, School of Biological, Earth and Environmental Sciences, University of New South Wales, Kensington NSW 2052, Australia

${ }^{d}$ NSW Office of Environment and Heritage, Hurstville NSW 2220, Australia

${ }^{e}$ Centre for Environmental Policy, Imperial College London, UK

${ }^{f}$ School of BioSciences, University of Melbourne, Parkville, 3010, Australia

${ }^{g}$ BirdLife International, David Attenborough Building, Cambridge, CB2 3QZ UK

${ }^{h}$ Department of Zoology, University of Cambridge, Downing Street, Cambridge CB2 3EJ, UK

${ }^{i}$ Conservation Programmes, Zoological Society of London, Regent's Park, NW1 4RY, UK

${ }^{j}$ Biology Department, University of California, Riverside, CA 92512, U.S.A.

${ }^{k}$ Conservation International, 2011 Crystal Drive, Suite 500, Arlington VA 22202 U.S.A.

${ }^{l}$ Centre for Biodiversity \& Environment Research, Department of Genetics, Evolution \& Environment, University College London, Gower Street, London, WC1E 6BT, U.K.

*Resit.Akcakaya@stonybrook.edu 


\begin{abstract}
Extinction of a species is difficult to detect, yet there are important conservation consequences of classifying an extant species as extinct or an extinct species as extant, and potentially significant costs of making the wrong classification. To deal with the uncertainties of detecting extinctions, some Critically Endangered species are tagged as 'possibly extinct' in the IUCN Red List. Recently developed methods allow calculating the probability that a species is already extinct, $P(E)$, based on threats, time series of records of the species, the intensity of targeted surveys and other factors. We review the potential costs and benefits of classifying extinct and extant species as extinct, possibly extinct, and extant. Benefits of correct classification include the correct estimation of extinction rates, correct analysis of extinction correlates, appropriate allocation of resources, and (if extinct) the recognition of loss of the species. Costs of incorrectly classifying extant species as extinct include the "Romeo error" (premature cessation of conservation, leading to the possible extinction of the species), and the loss of scientific credibility upon rediscovery of presumed extinct species. Costs of incorrectly classifying extinct species as extant include inefficient use of resources and underestimating extinction rates. Based on these costs and benefits, we propose a framework for setting thresholds of $P(E)$ for classifying species as extinct, possibly extinct, and extant.
\end{abstract}

Key words

extinction, cost-benefit, IUCN Red List 


\section{Contents}

1. Introduction

2. Costs and benefits

3. Probability thresholds for listing criteria

4. Estimating extinction rates

5. Dealing with uncertainty

6. Applying the proposed approach

7. Conclusions

Acknowledgments

References 


\section{Introduction}

Extinction of a species is difficult to detect, yet there are important consequences of classifying a species as extinct and potentially significant costs of making the wrong classification. The International Union for Conservation of Nature (IUCN) has defined the category Extinct (EX) to be used when 'there is no reasonable doubt that the last individual has died' (IUCN 2001). Listing a species as Extinct on the IUCN Red List requires that exhaustive surveys have been undertaken in all known or likely habitat throughout its historic range, at appropriate times (diurnal, seasonal, annual) and over a timeframe appropriate to its life cycle and life form (IUCN 2001, 2017).

Listing a species as Extinct (EX) on the IUCN Red List has significant conservation implications, because the IUCN Red List is widely regarded as the most authoritative system for classifying extinction risk (Rodrigues et al., 2006) and conservation measures, protective laws and resources are usually not applied to species believed to be extinct (e.g. U.S. Endangered Species Act 1972, European Union Birds Directive, Australian Environment Protection and Biodiversity Conservation Act 1999). On the other hand, failing to list extinct species as Extinct also has consequences, notably wasting resources on species that can no longer benefit from them and the underestimation of extinction rates, which are often used to report on the state of the environment and loss of biodiversity (Butchart et al., 2004, 2007, 2010; Commonwealth of Australia 2006, Rockström et al., 2009, SCBD 2010, UN 2010). To deal with this issue, Butchart et al. (2006) proposed a 'possibly extinct' designation as a tag added to the Critically Endangered (CR) category, $\mathrm{CR}(\mathrm{PE})$, to identify those species "that are, on the balance of evidence, likely to be extinct, but for which there is a small chance that they may be extant and thus should not be listed as Extinct until adequate surveys have failed to find the species and 
local or unconfirmed reports have been discounted". IUCN adopted this in 2008 (IUCN 2017). Taxa identified as possibly extinct are therefore included as an upper bound on the number of recent extinctions to indicate plausible uncertainty in contemporary rates of extinction (Butchart et al., 2006; Tittensor et al., 2014, IUCN 2017).

The categories EX and $\mathrm{CR}(\mathrm{PE})$ can be defined in terms of the probability that the species is already extinct, $P(E)$, which in turn can be estimated from data on threats (Keith et al., subm), observation records, and targeted surveys (Thompson et al., subm). The aim of this paper is to present a cost-benefit framework for determining the threshold values of this probability for placing a species in the categories EX and $\mathrm{CR}(\mathrm{PE})$.

In principle, if $P(E)$ can be calculated, there is no need to put each species into a category. Instead, one could simply cite $P(E)$. In other words, given the uncertainties involved in establishing that an extinction has occurred, there is no theoretical reason for defining categories and determining thresholds of $P(E)$ that separate them. Similarly, if extinction risk, the probability that a species will go extinct in the future, can be quantified, there is no need to put species into categories of extinction risk, such as Endangered and Vulnerable. However, there are practical reasons for using categories: it translates probabilities into natural language, making them easier to comprehend and communicate. Such language-based categories are used in the IUCN Red List not only for extinct and possibly extinct categories, but also for threatened species categories. The success of the IUCN Red List in communicating threats to biodiversity to the general public can be attributed in part to the use of categories instead of numerical scores. Language-based categories are also applied widely in risk analysis in other domains (e.g. Watson 1998, Ayyub 2001). In addition to facilitating communication, the use of categories provides a platform for analysts to make subjective judgments of risk in circumstances in which data are 
scarce. Many analysts may be more comfortable assigning a species to a risk category, than attempting to quantify $P(E)$.

If the broad objective is to minimize the overall costs of incorrect decisions, then the thresholds of $P(E)$ between $\mathrm{EX}$ and $\mathrm{CR}(\mathrm{PE})$ and between $\mathrm{CR}(\mathrm{PE})$ and $\mathrm{CR}$ should depend on the relative costs and benefits of making these listings for species that are actually extinct and actually extant. In general, a larger cost for listing an extant species as EX suggests a more strict (restrictive) criterion for EX (a higher $P(E)$ threshold), so that only species that have a very high likelihood of having already gone extinct would be listed as EX. On the other hand, a larger cost of listing an extinct species as threatened suggests a less strict criterion so that any species with a reasonable likelihood of having already gone extinct would be listed as EX. Thus, a careful examination of these costs and benefits is essential for determining appropriate thresholds.

The costs and benefits, in turn, depend on how listings are used (see Table 1). They have two important applications: (a) to decide which species to incorporate into analyses of extinction, its rates, causes and correlates, and (b) to determine which species should receive conservation resources (for searches for surviving populations and for interventions to improve their status). In general, only species listed either as $\mathrm{EX}$ or as $\mathrm{CR}(\mathrm{PE})$ are used in calculating rates of extinction and other analyses of extinct species (e.g. traits or other properties that characterize extinct species, threatening processes driving extinction, geography of extinctions) (Baillie et al., 2004, Butchart et al., 2006, BirdLife International 2010a, Szabo et al., 2012; Tittensor et al., 2014). Another approach, discussed below, is to weight each species in such analyses by its $P(E)$.

Resource allocation for species listed as $\mathrm{CR}(\mathrm{PE})$ may be prioritized by cost-effectiveness analysis (e.g. Joseph et al., 2009; Table 1). For possibly extinct species, the expected benefits of an activity would incorporate the probability that the species is not already extinct. Resources are 
usually made available for surveys designed to find whether (and where) CR(PE) species survive (e.g. BirdLife International 2010a), and for conservation actions in the areas where the species is expected to remain extant if these are well defined (e.g. Alliance for Zero Extinction sites: Ricketts et al., 2005; or Important Bird and Biodiversity Areas: BirdLife International 2014). For birds, when there is considerable uncertainty over the location of potentially surviving populations of $\mathrm{CR}(\mathrm{PE})$ species, conservation resources tend not to be allocated for interventions without first conducting surveys to locate remaining populations (BirdLife International 2008). Although we focus here on species, the framework we propose can also be applied to other taxonomic units, such as subspecies.

\section{Costs and benefits}

As mentioned above, if an extant species is listed as EX (a 'false positive' error), protective measures that might have saved the species may be discontinued, causing the species to become more threatened, or even leading to the extinction of the species. This has been called the 'Romeo Error' (Collar 1998), a term first used in the case of the Cebu Flowerpecker, Dicaeum quadricolor. The species was rediscovered in 1992 after 86 years without a record (Dutson et al., 1993) and presumed extinct at least 40 years earlier (Magsalay et al., 1995).

It is almost impossible to know if a species has become extinct via a Romeo Error, because it would require knowledge of the true date of extinction for a species that was prematurely listed as EX, the final event or threat that caused the extinction, and whether this event or threat could have been prevented if the species had been listed as CR or CR(PE) instead of EX. However, there are examples of species that have become more threatened as a result of being listed erroneously as EX. For instance, during the 40 years the Cebu Flowerpecker was 
presumed extinct, its forest habitat continued to be substantially reduced in extent and quality through clearance for agriculture and removal of timber and firewood (BirdLife International 2010b). It is likely that this species would currently be more secure had its existence been known and its habitat protected during this time, given that conservationists intervened to protect other Philippine endemics during this period.

Another example is the Leadbeater's Possum, Gymnobelideus leadbeateri, which was described in 1867 and was thought to have become extinct by the early 1900s (Le Souef and Burrell 1926, Troughton 1947). Throughout most of the 20th century, much of its habitat of old growth forests was harvested by clear felling. It was rediscovered in 1961, and was later declared endangered in Australia based on past and predicted future declines due to habitat loss (Lindenmayer et al., 1991, Lindenmayer and Possingham 1994). The conservation requirements precipitated changes in forest management practices after the 1980s (Macfarlane et al., 1997, Lindenmayer 2009). It is likely that these changes in forestry practices would have been implemented earlier if the species had not been presumed extinct.

There are other costs of listing an extant species as EX (Table 2). One is the loss of public confidence in listings if species are rediscovered (Roberts \& Kitchener 2006). It is important to note that the cost we are concerned with here is not the cost to scientists (e.g., the loss of face of the experts who made the original EX listing), but the conservation costs that result from loss of credibility (i.e. 'crying wolf')—for instance, if subsequent estimates of extinction risks and extinction rates, or other assessments of threat status made by scientists are not taken seriously by the public or government agencies, it may lead to weaker conservation measures for other species (Mann 1991; Kottelat 1994; Hobbs and Mooney 1998; Pye-Smith 1999). Such losses of credibility occurred following publicity around errors in the 
Intergovernmental Panel on Climate Change (IPCC) reports (Hanson 2010). Related to this is the cost of falsely blaming certain organizations (e.g. a timber company) or projects (e.g. construction of a particular highway) for causing a species' extinction, which may lead to costly litigation when the species is rediscovered or to the subsequent disregard of cautions about the possibility of similar projects causing other extinctions.

The rediscovery of species declared EX (the Lazarus effect) is rather common (Keith and Burgman 2004). Indeed, Miller et al. (1989) noted several examples of North American fishes that had been considered to be extinct only to be "rediscovered by surprised scientists." However, in many cases rediscovery requires considerable search effort. The rediscovery in the wild of the Mangarahara cichlid Ptychochromis insolitus in 2013 was only possible through a focused program of international consultation and fieldwork (Zimmerman 2014). The shrub, Haloragodendron lucassii, was rediscovered in a forest remnant within suburban Sydney (Australia) in 1986. An absence of records since 1926 had led to its Extinct listing. It was rediscovered when an amateur botanist was motivated to search for the species after its details were published in a book featuring extinct and endangered plants (Leigh et al., 1984). This story of rediscovery suggests that publicity associated with EX listings may sometimes have benefits in stimulating additional search effort (Moore 2014). In addition, the publicity associated with Lazarus species could potentially generate financial and political support to prevent the species from becoming extinct, although equally that publicity can create threats that were previously absent (Meijaard \& Nijman 2014).

In the case of umbrella (or flagship) species, listing the species as EX and subsequent termination of conservation actions may lead to a "closed umbrella" effect: cessation of existing conservation measures for other extant species that may have been benefiting collaterally from 
the conservation efforts for the umbrella species, and lost opportunities for future conservation actions, such as habitat restoration, that may benefit additional species. Leadbeater's Possum, mentioned previously, illustrates the cost of erroneously listing an umbrella species as EX. The old growth forest on which it depends harbors many other forest and old-growth dependent species. The perception that this important species was already lost meant that many such forests were logged, with concomitant consequences for the associated species.

Another cost might be anthropogenic Allee effect (Courchamp et al., 2006), if an erroneous EX listing causes increased demand for a species, e.g., as a collectible item. Although we did not find any specific instances of this, increased trade in species proposed to be uplisted to a more restrictive CITES status (Rivalan et al. 2007), higher price of rarer species (Courchamp et al. 2006), and wildlife traffickers stockpiling in the hope of profiting from the extinction of the species (i.e., 'banking on extinction'; Mason et al. 2012) suggest that it is a strong possibility.

There are also costs associated with failing to list an extinct species as EX (a 'false negative' error; Table 2). The most important cost is inefficient allocation of resources to a species that can no longer benefit from conservation measures. In some cases, other species may benefit from these misdirected conservation measures, but it is likely to be an inefficient use of resources. As with the Lazarus effect, there may be a loss of reputation and credibility when it is eventually realized that a species has been extinct for some time. A notable recent example is that of the Ivory-billed Woodpecker, Campephilus principalis, purportedly rediscovered in 2004. Millions of dollars were spent on its conservation (Mikusinski et al., 2010) and development of a recovery plan (USFWS 2010). However, after 5 years of intensive searches and no subsequent records after more than a decade, many believed that the claimed rediscovery was a case of “mistaken identity” (Dalton, 2005, 2010). 
If we fail to list an extinct species as EX we will underestimate current extinction rates. For example, extinctions documented on the IUCN Red List are likely to be a significant underestimate, even for well-known taxa such as birds (Butchart et al., 2006, Szabo et al., 2012). Similarly, Bruton (1995) believed that the numbers of extinct (and threatened) fishes may be significantly underestimated. This can lead to a falsely optimistic perception of ongoing threats and diminished motivation to reduce them. However, this cost could be significantly lower if consistent criteria are used to list species as $\mathrm{CR}(\mathrm{PE})$, and if such species are used in estimating extinction rates (Table 1). Below, we demonstrate how bounded estimates of extinction rates can be calculated from such categorizations.

The same types of costs apply to wrongly listing a species as $\mathrm{CR}(\mathrm{PE})$, although to a lesser extent. If the species is actually extinct, the resources allocated for it may be limited to searches (which are needed to confirm its status) if the locations of surviving populations are too uncertain to focus conservation interventions (Table 1). If the species is extant, including it in extinction analyses may not create substantial errors if the number of $\mathrm{CR}(\mathrm{PE})$ species are appropriately weighted (see below).

\section{Probability thresholds for listing criteria}

The costs and benefits discussed above are in the same units: the number of extinctions caused or avoided. Some of these costs and benefits (e.g., appropriate resource allocation or loss of scientific credibility) may appear to involve financial or other types of units, but they are considered here only in terms of their eventual effect on species conservation, in units of the future number of extinctions, treating all species equally. Although the common unit makes this framework conceptually simple, it does not necessarily mean that it is easy or even possible to 
quantify the costs or benefits, because of lack of knowledge on how each factor relates to extinction rates, and because of the uncertainties involved. As noted above, it is virtually impossible to know the number of species that have become extinct as a result of the Romeo Error. Because of its more immediate connection to a possible extinction, this error is most likely to result in the highest of the costs we reviewed; thus, attempting to quantify the costs would only lead to an incomplete and biased calculation.

Instead, we note that the overall conservation costs of listing an extant species as EX are likely to be far more serious than other errors, in terms of the number of future extinctions caused or avoided. This is because there are more types of costs of this error than the others (Table 2), and because one of these (specifically, the Romeo Error) is likely to be more costly than others. This suggests that the threshold of $P(E)$ for EX should be quite high, perhaps in the range 0.90 to 0.99 . In other words, species should be listed as EX only if we are very certain that the species is actually extinct. We believe this attitude, comparable to favoring the "extant unless proven extinct" approach discussed by Diamond (1987), is consistent with the current practice of conservative use of this category in the IUCN Red List. We recommend a threshold of 0.95; in other words, on average, the net cost of listing a single extant species as EX is considered to be equivalent to the net cost of failing to list twenty extinct species as EX.

It is more problematic to determine an appropriate threshold of $P(E)$ for $\mathrm{CR}(\mathrm{PE})$. On the one hand this should minimize the costs associated with underestimating extinction rates and potentially wasting conservation resources (suggesting the threshold should be quite low, perhaps 0.5 or lower). On the other hand, a low threshold may lead to a very large number of species being listed as $\mathrm{CR}(\mathrm{PE})$, the rediscovery of many of which (the Lazarus effect) may cause 
the loss of credibility and accusations of 'crying wolf'. This would suggest a higher threshold, perhaps as high as 0.8 .

We emphasize that both thresholds are necessarily subjective. Just as in the case of thresholds of future extinction risk that separate extant species into threat categories (such as Endangered and Vulnerable), there is no theoretical reason why the thresholds discussed here should not be subjective (Collen et al., 2016; IUCN 2017). Therefore, we recommend a process of testing and consultation to determine the numerical values of these thresholds to be used in the IUCN Red List. Work is currently underway to estimate $P(E)$ for all current and candidate CR(PE) bird species (updated from the list considered by Butchart et al., 2006), and these results plus those for a sample of other taxa should inform the recommendation for a threshold, which we suggest should then be ratified through a wide consultation process that involves conservation scientists and practitioners.

\section{Estimating extinction rates}

In this paper, we define extinction rate as the proportion of species (in a taxonomic group or in a region) that have gone extinct since 1500 (we discuss time frames below). If the probabilities of extinction of all species of conservation concern can be estimated, extinction rates should be based on the sum of these probabilities, rather than simply summing the numbers of species in various categories. This way, the estimated number of extinct species would be independent of the thresholds of $P(E)$ for EX and CR(PE). The proposed calculation is demonstrated in Table 3. The sum of $P(E)$ is an estimate of the number of extinct species; the extinction rate for the group is calculated by dividing this number by the total number of species in the group (Table 3). 
If $P(E)$ is not calculated for some species that are listed as $\mathrm{EX}$ or $\mathrm{CR}(\mathrm{PE})$, then the extinction rate should be calculated by assigning a weight to each such species. The weights should be based on the average $P(E)$ for species in the same taxonomic group with the same listing, for which $P(E)$ has been calculated. This assumes that the subset of species for which $P(E)$ has been calculated is an unbiased, representative sample of the full set of species in the group that qualify for $\mathrm{EX}$ or $\mathrm{CR}(\mathrm{PE})$. If there are no (or very few) species in the group for which $P(E)$ has been calculated, then the weights should be based on the midpoint of the range of $P(E)$ for that category. For example, if the $P(E)$ thresholds are 0.95 and 0.5 , for EX and $\mathrm{CR}(\mathrm{PE})$, respectively, then the weights should be 0.975 (mid-point of 0.95 to 1.0) and 0.725 (mid-point of 0.5 to 0.95 ), for species listed as EX and as $\mathrm{CR}(\mathrm{PE})$, respectively. Alternatively, if the $P(E)$ threshold is 0.8 for $\mathrm{CR}(\mathrm{PE})$ then the weight should be 0.875 for species listed as $\mathrm{CR}(\mathrm{PE})$.

EX listings in the IUCN Red List include species that have gone extinct since 1500, so extinction rates based on the IUCN Red List are calculated over a time period of about 500 years. However, if extinction times can be estimated for all species in a group, extinction rates can also be calculated over shorter or longer time periods (e.g. Butchart et al., 2006 and Szabo et al., 2010 calculated rates for birds over 25 -year periods since 1500 ). For example, to calculate the extinction rate over a 100-year period up to 2015 , species that are believed to have gone extinct before 1915 would be excluded, and $P(E)$ would be summed over the remaining species in the group, and the sum divided by the number of species believed to have been extant at the beginning of the time period.

\section{Dealing with uncertainty}


Using probability thresholds for EX and $\mathrm{CR}(\mathrm{PE})$ could exclude species that are extinct but are listed as CR because the estimated probability that they are already extinct is below the threshold for $\mathrm{CR}(\mathrm{PE})$. Depending on the thresholds, this may omit a relatively small number of extinct species from these categories. Of potentially greater concern is the number of Data Deficient species (see IUCN 2001) that may be extinct. However, Data Deficient species generally have no plausible threats based on direct information or indirect inference, e.g. from known trends in habitat (otherwise they would be listed as threatened), so should be unlikely candidates for extinction (Butchart and Bird 2009). The exceptions are those species listed as Data Deficient because they are of unknown provenance, in which case it is impossible to make any judgment about the likelihood of any threats. For example, Bogota Sunangel Heliangelus zusii is a hummingbird known from a single specimen purchased in 1909 in Bogotá, Colombia (but which may have come from as far as Venezuela or Peru: Graves, 1993; Kirchman et al.,, 2010). The Coppery Thorntail Discosura letitiae is another hummingbird known only from two specimens taken prior to 1852 (Bourcier and Mulsant, 1852) and labelled as from Bolivia (but which could have come from adjacent countries: Graves 1999). A proportion of such species may in fact be extinct. As such species are specifically flagged on the IUCN Red List, extinction rate estimates could be modified to include the number of such species multiplied by an extinction probability of 0.5 , assuming about half of them might already be extinct. For most taxonomic groups, there are very few such species, therefore the uncertainty around this assumption would have minimal effect on the estimated number of extinct species, although misclassification could have significant implications in individual cases.

Setting the $P(E)$ thresholds requires considering the types, amount and quality of information used in the estimation of $P(E)$. If the probability of extinction is estimated as the 
union of many uncertain events, all of which are estimated to two or fewer significant figures, very high thresholds such as 0.99 may fail to capture any species as extinct. Conversely, if qualitative information (such as life history traits or threats) is used to inform quantitative estimates of probabilities, or crude correlates of extinction or simple models are used to infer $P(E)$, lower thresholds for EX may capture too many false positives. The number of false positives depends on how biased these correlates or estimates are, the direction of the bias, how they are interpreted by assessors, the relationship of the correlate to mechanisms causing extinction and how qualitative information is converted to numerical probability estimates. This can be the case despite assignment of uncertainty bounds on $P(E)$ estimates or their constituent parameters. Hence, application of a $P(E)$ threshold should be coupled with compatible and consistent methods for estimating $P(E)$. We discuss such a method in the next section.

\section{Applying the proposed approach}

The usefulness of the cost-benefit framework presented here and application of $P(E)$ thresholds for EX and $\mathrm{CR}(\mathrm{PE})$ depend on unbiased estimation of $P(E)$ with methods that are both practical enough to be applied to species in all taxonomic groups, and that make structured, consistent, and transparent use of all relevant qualitative and quantitative information. The previous papers in this trilogy outline two complementary approaches for doing this (Figure 1). To estimate $P(E)$, Keith et al. (subm) use qualitative and, where available, quantitative information about the severity, duration and scope of threats and their interaction with the species' life history traits which determine its susceptibility to these threats. This is the "Threats Model" in Figure 1, and estimates $P(E \mid$ threats). Thompson et al. (subm) developed a quantitative approach that uses a time series of records of the species (and the absence of records 
resulting from passive surveillance in the intervening years) to calculate and iteratively update $P(E)$, including propagating the uncertainties associated with each uncertain record. This is the "Records Model" in Figure 1. If the species was subject to targeted surveys designed to detect it after the last known record, or to surveys within its potential range with a chance of opportunistically recording it, Thompson et al. (subm) modify $P(E)$ based on the timing, comprehensiveness and adequacy of these surveys. This is the "Surveys Model" in Figure 1. The "Records Model" and the "Surveys Model" are used iteratively, depending on whether, in a given year, there was a record or a survey that did not result in a record (in other years, passive surveys are assumed).

If the " $P(E \mid$ threats)" model of Keith et al. (subm) was used to determine $P(E)$ at the time the series of records commenced, then " $P(E \mid$ threats $)$ " can be used as the initial value, to be updated by the time series of records, using the model developed by Thompson et al. (subm). However, in most cases the threats model will provide an independent estimate $P(E)$ (as in the cases discussed by Keith et al., subm), rather than the initial value of $P(E)$ for the Records model. If independent estimates of $P(E \mid$ threats $)$ from the Threats model and $P(E \mid$ records, surveys $)$ from the Records and Surveys models are available, the assessors should consider both estimates, including their uncertainties. In cases with few and uncertain records and few surveys with limited spatial coverage, the Threats model of Keith et al. (subm) may be more reliable. In cases with recent and reliable records, or several extensive surveys, the Records and Surveys model of Thompson et al. (subm) may more closely estimate the probability that a species is extinct, as defined by IUCN ("last individual has died").

In principle, the proposed framework can be used with any method of estimating $P(E)$. In practice, however, methods that use data on threats, observation records, and targeted surveys are 
needed to determine the probability of being extinct for a wide range of taxa. Keith et al. (subm) is the only approach that uses qualitative and quantitative information on threats to calculate $P(E)$, and Thompson et al (subm) is the only method that uses data on both records and targeted surveys to do the same. These two approaches, used within the cost-benefit framework proposed here, allow categorization of extinct and possibly extinct species, and calculation of extinction rates (Fig. 1).

\section{Conclusions}

Assessing extinction status involves two kinds of decisions. First, there is a classification step in which species are categorized as extinct, possibly extinct or not extinct, based on the estimate of the probability that the species is extinct. A simple rule would compare the probability against the two thresholds, as discussed above.

Second, there is the more practical question of how a decision-maker should act when making decisions such as allocating resources to conservation efforts. Here, the considerations of costs and benefits are critical. Of course, as has been said, these costs and benefits vary from case to case so that even if the probability of extinction is the same, decisions may differ. Table 1 describes the broad ways in which listings are often used, but it is not intended to be prescriptive (except for the need to use weights for $\mathrm{CR}(\mathrm{PE})$ ). The behavior of decision makers, following the classification of the species, is the domain of each jurisdiction and decision, because these actions involve a raft of social and contextual criteria that are independent of the estimate of the probability of extinction. This view leads us to recommend that one set of thresholds should apply for all species, even though the costs and benefits of decisions following classification may be case-specific. As recommended above, these thresholds should be ratified through a wide 
consultation process convened by IUCN that involves conservation scientists and practitioners, considering the cost-benefit framework we have outlined here.

\section{Acknowledgments}

We thank the organizers and participants of the 2010 Extinction Workshop at Woods Hole Oceanographic Institute that discussed these issues and created the overall analytical framework discussed here. We thank F. Courchamp, T. Oldfield, S. Bachman, L. Gardiner, H. Beentje for information on demand and rarity. National Science Foundation supported H.R.A. (DEB1146198).

\section{References}

Ayyub, B. M. 2001. Elicitation of expert opinions for uncertainty and risks. CRC Press, Boca Raton.

Baillie, J.E.M., Hilton-Taylor, C. \& Stuart, S., Eds. 2004. A Global Species Assessment. xxiv + 191 p. IUCN - The World Conservation Union, Gland, Switzerland, and Cambridge, UK.

BirdLife International. 2008. Critically Endangered birds: a global audit. Cambridge, UK: Birdlife International.

BirdLife International. 2010a. State of the world's birds. Available at: http://www.birdlife.org/sowb

BirdLife International. 2010b. Species factsheet: Dicaeum quadricolor. Available at: $\underline{\text { http://www.birdlife.org/datazone/species/index.html?action=SpcHTMDetails.asp\&sid=8203 }}$ $\underline{\& m=0}$ 
BirdLife International. 2014. Important Bird and Biodiversity Areas: a global network for conserving nature and benefiting people. Cambridge, UK: BirdLife International. Available at http://www.birdlife.org/datazone/sowb/sowbpubs\#IBA

Bourcier, J., Mulsant, E. 1852. Description de quelques nouvelles esp ̃̃"ces d'oiseaux-mouches. Annales des Sciences Physiques et Naturelles de Lyon 4, 139-144.

Bruton, M. N. 1995. Have fish had their chips? The dilemma of threatened fishes. Environmental Biology of Fishes 43, 1-27

Butchart, S.H.M., Stattersfield, A., Brooks, T.M. 2006. Going or gone: defining 'Possibly Extinct' species to give a truer picture of recent extinctions. Bulletin of the British Ornithologists' Club 126, 7-24.

Butchart, S. H. M., Bird, J. 2009. Data Deficient birds on the IUCN Red List: what don't we know and why does it matter? Biol. Conserv. 143, 239-247.

Butchart, S.H.M., Stattersfield, A.J., Bennun, L.A., Shutes, S.M., Akçakaya, H.R., Baillie, J.E.M., Stuart, S.N., Hilton-Taylor, C., Mace, G.M. 2004. Measuring global trends in the status of biodiversity: Red List Indices for birds. Public Library of Science - Biology 2, 2294-2304.

Butchart, S.H.M., Akçakaya, H.R., Chanson, J., Baillie, J.E.M., Collen, B., Quader, S., Turner, W.R., Amin, R., Stuart, S.N., Hilton-Taylor, C., Mace, G.M. 2007. Improvements to the Red List Index. PLoS ONE 2(1), e140.

Butchart, S.H.M., et al., 2010. Global biodiversity: indicators of recent declines. Science 328, 1164-1168.

Collar, N.J. 1998. Extinction by assumption; or the Romeo Error on Cebu. Oryx 32, 239-243 
Collen, B., Dulvy, N.K., Gaston, K.J., Gärdenfors, U., Keith, D.A., Punt, A.E., Regan, H.M., Böhm, M., Hedges, S., Seddon, M., Butchart, S.H.M., Hilton-Taylor, C., Hoffmann, M., Bachman, S.P. Akçakaya, H.R. 2016. Clarifying misconceptions of extinction risk assessment with the IUCN Red List. Biology Letters 12, 20150843.

Commonwealth of Australia 2006. Australian State of Environment Report 2006. Department of Environment and Heritage, Canberra.

Courchamp F., Angulo E., Rivalan P., Hall R.J., Signoret L., Bull, L., Meinard Y. 2006. Rarity value and species extinction: the anthropogenic Allee effect. PLoS Biology 4(12), e415.

Dalton, R. 2005. Sighting of 'extinct' bird may have been a case of mistaken identity. Nature, $436,447$.

Dalton, R. 2010. Still looking for that woodpecker. Nature, 463, 718.

Diamond, J.M. 1987. Extant unless proven extinct? Or extinct unless proven extant? Conservation Biology 1, 77-79.

Dutson, G. C. L., Magsalay, P. M., Timmins, R. J. 1993. The rediscovery of the Cebu Flowerpecker Dicaeum quadricolor, with notes on other forest birds on Cebu, Philippines. Bird Conserv. Intern. 3, 235-243.

Graves, G. R. 1993. Relic of a lost world: a new species of sunangel (Trochilidae: Heliangelus) from "Bogotá". The Auk 110, 1-8.

Graves, G. R. 1999. Taxonomic notes on hummingbirds (Aves: Trochilidae,) 2. Popelairia letitiae (Bourcier \& Mulsant, 1852) is a valid species. Proceedings of the Biological Society of Washington 112, 804-812.

Hanson, B. 2010. Editorial: Stepping back; moving forward. Science 328, 667. 
Hobbs, R.J., Mooney, H.A. 1998. Broadening the extinction debate: population deletions and additions in California and Western Australia. Conservation Biology 12, 271-283.

IUCN 2001. IUCN Red List Categories and Criteria: Version 3.1. IUCN Species Survival Commission. IUCN, Gland, Switzerland and Cambridge, U.K. ii + 30pp.

IUCN 2017. Guidelines for Using the IUCN Red List Categories and Criteria. Version 13. Prepared by the Standards and Petitions Subcommittee. Downloadable from http://www.iucnredlist.org/documents/RedListGuidelines.pdf.

Keith, D. A., Burgman, M. A. (2004). The Lazarus effect: can the dynamics of extinct species lists tell us anything about the status of biodiversity? Biological Conservation 117, 41-48.

Keith, D. A., et al.,(subm). Inferring extinctions I: A structured method using information on threats.

Kirchman, J. J., Witt, C. C., McGuire, J. A., Graves, G. R. 2010. DNA from a 100-year-old holotype confirms the validity of a potentially extinct hummingbird species. Biology Letters $6,112-115$.

Kottelat, M. 1994. Scriptor pretentiosus ist keine bedrohte Art. Dtaz Aquarien Terr. 47, 172-173

Le Souef, A.S., Burrell, H. 1926. The wild animals of Australasia, embracing the mammals of New Guinea and the nearer Pacific Islands, with a chapter on the bats of Australia and New Guinea by Ellis Le G. Troughton. George G. Harrap \& Company Ltd., London.

Leigh, J.H., Briggs, J.D.,Hartley, W.,1981. Rare or threatened Australian Plants. Special Publication No. 7. Australian National Parks and Wildlife Service, Canberra.

Leigh, J. H., Boden, R., Briggs, J. D. 1984. Extinct and Endangered plants. World Wildlife Fund MacMillan, Melbourne. 
Lindenmayer, D.B., Cunningham, R.B., Nix, H.A., Tanton, M.T., Smith, A.P. 1991. Predicting the abundance of hollow-bearing trees in montane forests of southeastern Australia. Australian Journal of Ecology 16, 91-8.

Lindenmayer, D.B. 2009. Old forest, new perspectives-Insights from the Mountain Ash forests of the Central Highlands of Victoria, south-eastern Australia. Forest Ecology and Management 258, 357-365.

Lindenmayer, D.B., Possingham, H.P. 1994. The risk of extinction: ranking management options for Leadbeater's Possum using population viability analysis. Centre for Resource and Environmental Studies, the Australian National University: Canberra

Macfarlane, M., Smith, J., Lowe, K. 1997. Leadbeater's Possum (Gymnobelideus leadbeateri) Recovery Plan. Flora and Fauna Program, Department of Natural Resources and Environment Victoria, July 1997. http://www.environment.gov.au/biodiversity/threatened/publications/recovery/leadbeaterspossum/index.html (accessed May 10, 2016).

Magsalay, P., Brooks, T., Dutson, G., Timmins, R. 1995. Extinction and conservation on Cebu. Nature 373, 294.

Mann, C.C. 1991. Extinction: are ecologists crying wolf? Science 253, 736-738.

Mason, C.F., Bulte, E.H., Horan, R.D., 2012. Banking on extinction: endangered species and speculation. Oxford Review of Economic Policy 28,180-192.

Meijaard, E., Nijman, V. 2014. Secrecy conditions for conserving Lazarus species. Biological Conservation 175, 21-24.

Mikusinski, G., Blicharska, M., Baxter, P.W. 2010. Costs and benefits of ivory-billed woodpecker "re-discovery". Frontiers in Ecology and the Environment 8, 460-460. 
Miller, R.R., Williams, J.D., Williams, J.E. 1989. Extinctions of North American fishes during the past century. Fisheries14, 22-38.

Moore, R. 2014. In search of lost frogs: the quest to find the world's rarest amphibians.

Bloomsbury Natural History, UK. 256 pp

Pye-Smith, C. 1999. Truth games. New Scientist 161, 16-17.

Ricketts, T. H., Dinerstein, E., Boucher, T., Brooks, T. M., Butchart, S. H. M. et al., 2005. Pinpointing and preventing imminent extinctions. Proceedings of the National Academy of Sciences, USA 102,18497-18501

Rivalan, P., Delmas, V., Angulo, E., Bull, L.S., Hall, R.J., Courchamp, F., Rosser, A.M., LeaderWilliams, N. 2007. Can bans stimulate wildlife trade? Nature 447,529-530.

Roberts, D.L. Kitchener, A.J. 2006. Inferring extinction from biological records: Were we too quick to write off Miss Waldron's Red Colobus Monkey (Piliocolobus badius waldronae)? Biological Conservation 128, 285-287.

Rockström, et al., 2009. A safe operating space for humanity. Nature 461, 472-475.

Rodrigues, A. S. L., Pilgrim, J. D., Lamoreux, J. L., Hoffmann, M., Brooks, T.M. 2006. The value of the IUCN Red List for conservation. Trends in Ecology \& Evolution 21, 71-76. SCBD 2010. Secretariat of the CBD - Global Biodiversity Outlook 4.

Szabo, J. K., Khwaja, N., Garnett, S. T., Butchart, S. H. M. 2012. Global patterns and drivers of avian extinctions at the species and subspecies level. PloS ONE 7, e47080.

Tittensor, D.A., et al., 2014. A mid-term analysis of progress toward international biodiversity targets. Science 346, 241-244.

Thompson, C.J., Lee, T.E., Stone, L., McCarthy, M.A., Burgman, M.A. 2014. Inferring extinction risks from sighting records. Journal of Theoretical Biology 338, 16-22. 
Thompson, C.J., Koshkina, V., Burgman, M.A., Butchart, S. H. M., Stone, L. (subm). Inferring extinctions II. An iterative model based on records and surveys..

Troughton, E. 1947. Furred Animals of Australia. New York, Charles Scribner's Sons.

UN 2010. United Nationals Millennium Development Goals Report 2010. New York: United Nations.

USFWS 2010. Recovery plan for the Ivory-billed Woodpecker (Campephilus principalis). USFWS Southeast Region, Atlanta, GA. Available online at www.fws.gov/ivorybill/pdf/IBWRecoveryPlan2010.pdf.

Watson, P. 1998. A process for estimating geological risk of petroleum exploration prospects. APPEA Journal 1998, 577-582.

Zimmerman, B. 2014. In search of the Mangarahara cichlid. Saving Freshwater Fishes and Habitats: Newsletter of the IUCN SSC/WI Freshwater Fish Specialist Group. Issue 4, March 2014, 17-22. http://www.iucnffsg.org/wp-content/uploads/2013/05/FFSG-NewsletterMarch-2014-Small.pdf 
Table 1. Use of listings in analyses of extinctions and in allocation of conservation resources

\begin{tabular}{|c|l|l|}
\hline Listing & $\begin{array}{c}\text { Use data from species in } \\
\text { analyses of extinct species? }\end{array}$ & \multicolumn{1}{|c|}{ Allocate resources for the species? } \\
\hline EX & Yes & No \\
\hline CR(PE) & $\begin{array}{l}\text { Yes; should be weighted } \\
\text { appropriately }\end{array}$ & $\begin{array}{l}\text { Yes for surveys; } \\
\text { Yes for conservation if location(s) known }\end{array}$ \\
\hline CR & No & Yes \\
\hline
\end{tabular}



italics are explained in the text.

\begin{tabular}{|c|c|c|}
\hline \multirow[t]{2}{*}{ Listing } & \multicolumn{2}{|c|}{ Costs and benefits of the listing ... } \\
\hline & ... if the species is extinct & ... if the species is extant \\
\hline EX & $\begin{array}{l}\text { Cost: Closed umbrella effect: cessation of collateral } \\
\text { benefits if an umbrella species is no longer conserved. } \\
\text { Benefits: (1) Correct estimation of extinction rates. (2) } \\
\text { Correct analysis of extinction correlates. } \\
\text { (3) Appropriate allocation of resources. } \\
\text { (4) Recognition of loss of the species. }\end{array}$ & $\begin{array}{l}\text { Costs: (1) Romeo error: Premature cessation of } \\
\text { conservation leading to the extinction of the species. } \\
\text { (2) Crying wolf (loss of scientific credibility)_-potentially } \\
\text { higher cost with greater public interest for the species. } \\
\text { (3) False accusation of individual(s)/ organization(s) as } \\
\text { causing extinction, with possible backlash and lawsuit. } \\
\text { (4) Closed umbrella effect: cessation of collateral benefits } \\
\text { if an umbrella species is no longer conserved. } \\
\text { (5) Anthropogenic Allee effect: increased demand, e.g., as a } \\
\text { collectible. } \\
\text { Benefits: (1) Stimulating surveys by amateurs that may } \\
\text { lead to rediscovery. }\end{array}$ \\
\hline
\end{tabular}




\begin{tabular}{|c|c|c|}
\hline & & $\begin{array}{l}\text { (2) Publicity surrounding rediscovery may generate } \\
\text { support. }\end{array}$ \\
\hline CR(PE) & $\begin{array}{l}\text { Cost: Some waste of resources (for surveys, and } \\
\text { potentially for conservation action, if location known, } \\
\text { interventions implemented, and no/low collateral } \\
\text { benefits). } \\
\text { Benefits: (1) Correct estimation of extinction rates. } \\
\text { (2) Correct analysis of extinction correlates. }\end{array}$ & $\begin{array}{l}\text { Cost: (1) Incorrect extinction analysis (unless } P(E) \text { is used } \\
\text { instead of counts of species). } \\
\text { (2) Crying wolf (see above, noting that the cost of this in } \\
\text { relation to a CR(PE) taxon is lower than for one classified } \\
\text { as EX. } \\
\text { Benefit: Appropriate resource allocation }\end{array}$ \\
\hline CR & $\begin{array}{l}\text { Costs: (1) Inefficient use of conservation resources. } \\
\text { (2) Underestimating extinction rates. } \\
\text { (3) Loss of credibility (not as costly as crying wolf). }\end{array}$ & $\begin{array}{l}\text { Benefits: (1) Correct allocation of resources (may lead to } \\
\text { avoidance of extinction). } \\
\text { (2) Correct estimation of extinction rates. } \\
\text { (3) Correct analysis of extinction correlates. }\end{array}$ \\
\hline
\end{tabular}


5 Table 3. Hypothetical example of calculating extinction rate for a taxonomic group comprising

$6 n=50$ species, for each of which the probability that it is extinct, $P(E)$, has been calculated. The

7 sum of $P(E)$ is an estimate of the number of extinct species; the extinction rate for the group is

8 calculated by dividing this number by the total number of species in the group, $(\Sigma P(E)) / n$. The

9 listings are based on the thresholds of 0.95 and 0.5 , for EX and CR(PE), respectively. Note that

10 the calculated extinction rate is independent of these example thresholds. CR listing means that

11 the species meets IUCN Red List criteria for Critically Endangered (IUCN 2001), in addition to

12 not meeting the suggested $P(E)$ threshold for $\mathrm{CR}(\mathrm{PE})$.

13

\begin{tabular}{lcc} 
Species & $\boldsymbol{P}(\boldsymbol{E})$ & Listing \\
\hline Species 1 & 0.41 & $\mathrm{CR}$ \\
Species 2 & 0.82 & $\mathrm{CR}(\mathrm{PE})$ \\
Species 3 & 0.97 & EX \\
Species 4 & 0.34 & $\mathrm{CR}$ \\
Species 5 & 0.21 & $\mathrm{CR}$ \\
Species 6 & 0.02 & $\mathrm{CR}$ \\
Species 7 & 0.64 & $\mathrm{CR}(\mathrm{PE})$ \\
Species 8 & 0.95 & $\mathrm{EX}$ \\
Species 9 - 12 & 0.00 & $\mathrm{EN}$ \\
Species 13 - 20 & 0.00 & VU \\
Species 21 - 25 & 0.00 & NT \\
Species 26 - 50 & 0.00 & LC \\
\hline Total of $\boldsymbol{P}(\boldsymbol{E})$ & 4.36 & \\
\hline
\end{tabular}

Extinction rate $8.72 \%$ 


\section{Factors considered Probability models}

\section{Outputs}

- Inferred susceptibility of the species to threats

- Threat severity

- Threat scope

- Threat timing
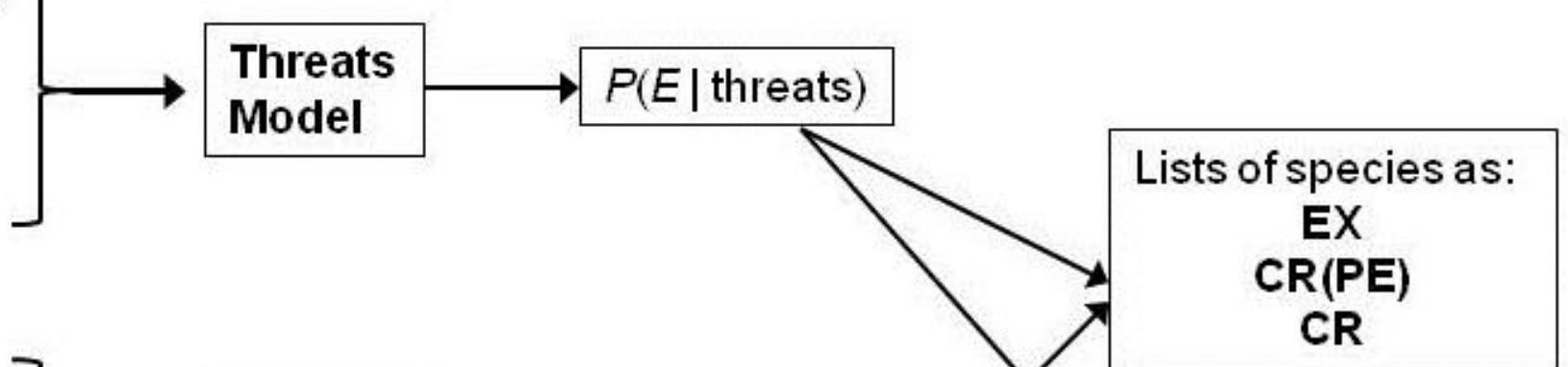

- Time series of records

- Probability of correct identification
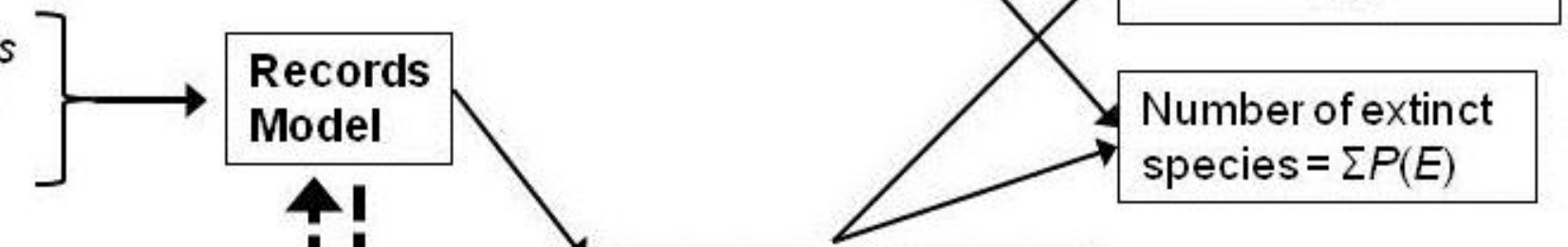

- \% range surveyed

- Probability of detection

- Probability of correct identification

\section{Surveys}

$P(E \mid$ records, surveys $)$

Figure 1. The proposed framework for calculating the probability that a species is extinct. The framework envisions using probability models that include information on threats, records, and targeted surveys to obtain, for each species, the probability that it is extinct and its listing, as well as the number of extinct species (as the sum of $P(E)$ ). The threats model, $P(E \mid$ threats), is explained in Keith et al. (subm), and the other two models in Thompson et al. (subm). The dotted arrows indicate that Records and Surveys models are used iteratively, depending on what occurred in a given year. 